\title{
Design centrado no usuário: uma estratégia de diferenciação no desenvolvimento de aplicativos móveis
}

\section{User-centred design: a differentiating strategy in mobile application development}

\section{Stephania Padovani}

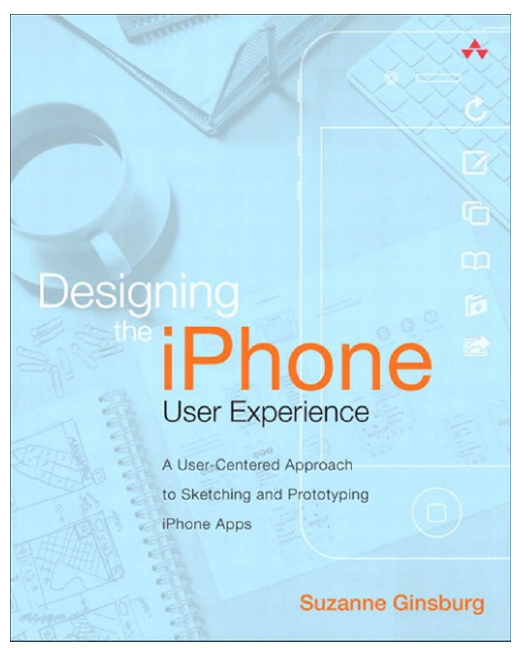

\author{
GINSBURG, Suzanne. Designing the iPhone user \\ experience: a user-centered approach to sketching \\ and prototyping iPhone apps. Boston: Addison-Wesley, \\ 2011. 294p. (ISBN 13: 978-0-321-69943-5)
}

\section{Sinopse}

Considerando a situação competitive dos applicativos para iPhone, diferenciar seu aplicativo tem se tornado cada vez mais desafiador para os designers. Atualmente, os usuários possuem muitas opções e se o seu app é difícil de usar ou não atende às necessidades do público alvo, encontrar outro está a apenas um click de distância. Mais ainda, apps bem projetados têm maior probabilidade de atrair e fidelizar usuários. Claramente, há outros aspectos crítico no desenvolvimento de apps para iPhone, como a programação, o marketing e o suporte ao consumidos, os quais devem trabalhar em conjunto. Designing the iPhone User Experience enfoca a parte da experiência do usuário no desafio de projetar para iPhone. Três temas se destacam ao longo do livro: Conheça seu usuário, Pratique o design interativo e Dedique atenção aos detalhes.

\section{Book description}

Given the competitive state of iPhone apps, it has become increasingly challenging for app designers to differentiate their apps. Users now have several choices and if your app is difficult to use or doesn't meet their needs, finding another one is just a tap away. Moreover, well-designed apps are more likely to attract and retain users. Of course there are also other critical aspects of iPhone app development, such as coding, marketing or customer support, which have to work together. Designing the iPhone User Experience focuses on the user experience part of the iPhone design challenge. Three key themes are reinforced throughout the book: Know thy user, Practice iterative design, and Attention to Detail.

\section{Introdução}

Imagine um equipamento sem cabos, que esteja sempre com você, que você possa operar com suas próprias mãos e que isso seja suficiente para que você esteja sempre conectado, a qualquer hora... em qualquer lugar... com qualquer pessoa... para fazer o que você quiser! Bom, agora pare de sonhar... esse equipamento já existe e o nome dele é smartphone. 
O smartphone pode ser considerado uma evolução dos telefones celulares, havendo incorporado progressivamente uma série de características que o tornaram mais sofisticado em termos tecnológicos e mais "amigável" em termos humanos. Atualmente, espera-se de um smartphone genérico que este possua uma tela multitouch, diversos dispositivos de entrada e saída multimídia (e.g., tocadores de música e câmera de vídeo/ foto digital), acesso à internet (e redes sociais), uma gama de aplicativos de utilidade específica, de produtividade e/ou de imersão/entretenimento. Mais do que isso, espera-se que estes aplicativos nos satisfaçam funcional e/ou ludicamente, que seja possível inclusive personaliza-los ou, caso contrário... desinstalamos e baixamos outro aplicativo.

Claramente, a fase entusiasta da tecnologia móvel (em que poder interagir em mobilidade era suficiente para a maioria do público) passou e os usuários estão se tornando cada vez mais exigentes. Centenas de milhares de aplicativos móveis estão hoje disponíveis, por exemplo, na App Store, o que permite que o usuário se torne mais seletivo e que a concorrência aumente progressivamente neste nicho de mercado. Por outro lado, para os designers, isso significa maiores desafios de projeto e maior dificuldade em diferenciar o app que estejam desenvolvendo.

O livro de Suzanne Ginsburg vem suprir uma lacuna de literatura específica para o desenvolvimento de interfaces de aplicativos em dispositivos de interação móvel (DIM), contrastando com a geração anterior de publicações sobre DIMs que adotou uma abordagem bastante generalista. Cumpre reconhecer que esta abordagem mais genérica e exploratória, foi extremamente necessária para estabelecer as fundações teóricas e metodológicas para amadurecimento da pesquisa na área. Autores como, por exemplo, Weiss (2002), Love (2005) e Ballard (2007) ainda são frequentemente citados quando se necessita definir e diferenciar a interação humano-computador móvel, discutir sobre as características do usuário móvel e buscar princípios gerais (principalmente de base cognitiva) para o desenvolvimento de interfaces em DIMs. Tais autores também sinalizaram uma série de desafios metodológicos e questões novas para fomentar a pesquisa na área.

Designing the iPhone user experience vem, portanto, revisar a abordagem de design centrado no usuário no contexto móvel, explicando pormenorizadamente como aplica-la ao desenvolvimento de aplicativos para iPhone, utilizando para tal, três principais axiomas: Conheça seu usuário, Pratique o design iterativo e Dedique atenção aos detalhes.

\section{Conheça seu usuário}

Ginsburg inicia sua argumentação a favor do design centrado no usuário comentando sobre as milhões de pessoas que atualmente dependem de aplicativos para iPhone para as mais diversas atividades cotidianas (e.g., trabalhar, solicitar refeição, conectar-se com família ou amigos). A autora destaca ainda que os aplicativos para iPhone também se destinam a profissionais com necessidades mais específicas, como por exemplo, médicos que consultam sobre interações medicamentosas, fotógrafos que precisam ajustar a iluminação de suas fotografias, ciclistas que necessitam encontrar a melhor rota. Portanto, para entender como os aplicativos podem fazer parte da vida dos usuários, Ginsburg defende que os designers e desenvolvedores precisam aprender como os usuários agem hoje, entender o que eles consideram importante e identificar necessidades ainda não foram supridas na forma de aplicativos. Como exemplo de técnica eficiente para descobrir as necessidades dos usuários, a autora cita a entrevista contextual.

\section{Pratique o design iterativo}

Ginsburg afirma que projetos premiados e aprovados pelo público raramente acontecem da noite para o dia. Usualmente, estes projetos envolvem uma série de rigorosos ciclos de design (o que se convencionou chamar de design iterativo, ou seja, cíclico). A autora reforça também que, essas iterações devem ocorrer antes que o aplicativo seja efetivamente lançado no mercado, o que economizará tempo e recursos financeiros. Ginsburg acredita ainda que "você terá apenas uma chance para impressionar seus usuários - portanto, não tente vender-Ihes idéias prematuras".

\section{Dedique atenção aos detalhes}

Apesar deste postulado ser senso comum entre profissionais de interface, Ginsburg adverte que centenas de aplicativos movéis falham em incorporar mesmo os princípios mais elementares de design. Essa falta de atenção, segundo a autora, não se restringe apenas à parte estética do aplicativo, afetando também sua parte funcional. Como forma de ilustrar seu argumento, Ginsburg cita, na mídia impressa, as notícias com alinhamento inadequado, que se tornam difíceis de ler e ícones mal projetados que se tornam difíceis de interpretar. Em síntese, a autora defende que 
aplicativos que se preocupem com os mínimos detalhes destacar-se-ão frente à concorrência e funcionarão muito melhor.

\section{Antes de começar: Conhecendo o iPhone e suas classes de aplicativo}

Na primeira parte de Designing the iPhone user experience, Ginsburg descreve o funcionamento do iPhone, com ênfase nas tecnologias de hardware que possibilitam a experiência do usuário neste tipo de aparelho (e.g., display multitouch, sensores de movimento). Ainda nesta parte de fundamentos, a autora revisa as três principais classificações para aplicativos - produtividade, utilidade e imersão e introduz o HIG (Human Interface Guidelines), ambos disponibilizados pela própria Apple para profissionais interessados em desenvolver aplicativos móveis.

\section{Pontos de interesse (segundo a autora desta resenha):}

- Ginsburg não se restringe a apresentar as características de hardware do iPhone, explorando sim as implicações dessas características para o desenvolvimento de aplicativos;

- Além de apresentar (de forma ricamente ilustrada) as três classes de aplicativos da Apple (produtividade, utilidade e imersão), Ginsburg discute as vantagens e desvantagens de cada categoria e traz dicas importantes sobre como selecionar a categoria de aplicativo a desenvolver.

\section{Definindo seu aplicativo para iPhone}

Na segunda parte de Designing the iPhone user experience, Ginsburg revisa uma série de métodos e técnicas de pesquisa com usuários, com destaque para o shadowing, entrevistas contextuais e diferentes formas de diário. Em seguida, a autora apresenta um passo-a-passo para a análise dos resultados das pesquisas com usuários, transformando esses dados em ferramentas intermediárias de projeto, como por exemplo, personas, cenários e user journeys. Por fim, a autora explica como conduzir análises de experiência do usuário para os competidores do aplicativo em desenvolvimento e, mais uma vez, explica como esses resultados podem auxiliar o designer a gerar a Definição do Aplicativo (Product Definition Statement).

\section{Pontos de interesse (segundo a autora desta resenha):}

- Além de explicar os métodos e técnicas, Ginsburg orienta o designer sobre como montar arranjos metodológicos para envolver os usuários do aplicativo em questão;

- A autora sempre relaciona os resultados das pesquisas com as fases posteriores do projeto, explicando didaticamente como sintetiza-los e extrair informações importantes para o design do aplicativo;

- Para facilitar o entendimento e trazer maior credibilidade às explicações, Ginsburg apresenta estudos de caso de como empresas colocaram isso em prática.

\section{Desenvolvendo o conceito do aplicativo}

Na terceira parte de Designing the iPhone user experience, Ginsburg explica como traduzir os achados da fase anterior em soluções de design para os aplicativos. Inicialmente, a autora orienta sobre como criar um ambiente amigável e conseguir sessões de brainstorming que sejam produtivas e eficazes. Em seguida, a autora apresenta as diferentes abordagens de prototipagem para aplicativos iPhone, desde a baixa fidelidade em papel, passando por software e culminando com a prototipagem em vídeo. Por fim, Ginsburg descreve vários métodos de avaliação de usabilidade, enfocando desde os mais tradicionais até os "testes de guerrilha", com ênfase no RITE (Rapid Iterative Testing and Evaluation).

\section{Pontos de interesse (segundo a autora desta resenha):}

- Além de orientar sobre o brainstorming, Ginsburg traz preciosas dicas sobre como ilustrar e comunicar explorações iniciais de design (soluções ainda preliminares), sugerindo diferentes tipos de sketch e explicando sobre o que priorizar nos sketches iniciais; 
- Na fase de prototipagem a autora auxilia o designer a escolher a melhor forma de prototipagem para seu aplicativo;

- Destaque para a Usability testing timeline (passo-a-passo extremamente detalhado sobre todas as etapas envolvidas nesse processo: planejamento, recrutamento, piloto, testes, análise e apresentação).

\section{Refinando seu aplicativo para iPhone (parei aqui)}

Na quarta parte de Designing the iPhone user experience, Ginsburg apresenta algumas das melhores práticas do design de interfaces em aplicativos móveis, além de princípios gerais que possuem aplicação em diferentes tipos de aplicativos móveis. Em seguida, trata de aspectos mais específicos do design visual, abordando estrutura gráfica (agrupamento, hierarquia e alinhamento) e detalhamento gráfico (uso de atributos gráficos para reforçar a estrutura e criar unidade visual). Já os últimos capitulos trazem temas complementares ao design de aplicativos móveis, enfocando branding, uso de propaganda, acessibilidade e localização.

\section{Pontos de interesse (segundo a autora desta resenha):}

- Balanço entre princípios gerais e recomendações específicas para o design visual;

- Ligação entre estrutura gráfica e detalhamento gráfico (atributos escolhidos - cor, tipografia, imagem - têm a função principal de reforçar a estrutura);

- Apesar do destaque do livro ser o envolvimento do usuário, esta parte também traz as melhores práticas que o próprio mercado vem revelando.

\section{Considerações finais}

O livro de Ginsburg contribui para a desmistificação do design centrado no usuário, ao trazer uma abordagem que se, por um lado, é bem fundamentada em termos teórico-metodológicos, ao mesmo tempo se mostra prática e flexível para se adaptar a diferentes situações de projeto. $\mathrm{O}$ texto é claro, preciso e didático, com passo-a-passos esclarecedores e ricamente ilustrados. Estudos de casos mostrando como os diferentes métodos, técnicas e procedimentos vêm sendo adotados em empresas também contribuem para facilitar o entendimento e fornecem maior credibilidade para o leitor que vem do mercado. Nesse sentido, julgo a obra atraente tanto para estudantes de graduação e pós-graduação em design e áreas afins, quanto para profissionais de design que tenham interesse em adentrar ou se aprofundar na área de desenvolvimento de interfaces para aplicativos móveis.

\section{Referências}

BALLARD, B. 2007. Designing the mobile user experience. West Sussex: John Wiley \& Sons.

LOVE, S. 2005. Understanding mobile human-computer interaction. Oxford: Elsevier

WEISS, S. 2002. Handheld usability. London: John Wiley \& Sons.

\section{Sobre a autora}

Stephania Padovani é graduada em Desenho Industrial pela ESDI-UERJ (1996), mestre em Design pela PUC-RJ (1998) e doutora em Ergonomia Cognitiva pela Loughborough University (Inglaterra). É professora e pesquisadora do Departamento de Design e do Programa de Pósgraduação em Design da UFPR. Suas principais áreas de atuação são ergonomia da interação humano-computador, web design e design da informação, com enfoque nos temas de navegação em hipermídia, usabilidade de interfaces e métodos de design centrado no usuário. Seu principal projeto de pesquisa em andamento atualmente intitula-se "Navegação em smartphones: uma abordagem centrada no usuário".

<s_padovani2@yahoo.co.uk>

[Artigo recebido em dezembro de 2012, aprovado em dezembro de 2012] 